\title{
From the editor-endings and beginnings in 2009
}

doi:10.1111/j.1751-8369.2009.00129.x

As the International Polar Year (IPY) drew to its conclusion earlier this year, so did the Norwegian-American Scientific Traverse of East Antarctica. Led by Norwegian Polar Institute (NPI) director Jan-Gunnar Winther, the first stage of the two-stage expedition took place in the austral summer of 2007/08. The Norwegian-American team travelled from the Norwegian research station Troll to a point about $350 \mathrm{~km}$ shy of the South Pole (see my editorial in Polar Research 27[1]). Along the way, they extracted ice cores, planted snow stakes mounted with GPS devices, deployed automatic weather stations, surveyed the route using several types of radar and collected an array of meteorological, glaciological and other data. The journey took two months.

The second half of the expedition kicked off on 23 December 2008. Tom Neumann of NASA's Goddard Space Flight Center led the 12-person team, which started from the US Amundsen-Scott South Pole Station. This time, the route back to Troll took the expedition over the Recovery Lakes. These vast-up to $1500 \mathrm{~km}^{2}$ subglacial lakes were revealed by satellite data in 2006. They lie at the head of the Recovery Ice Stream, among the largest glaciers draining East Antarctica. The team used radar and high-precision gravity and GPS measurements to map the surface topography, ice thickness, ice layering and gravity variation over and around the lakes. Low-frequency radar surveys showed that two of the lakes are connected, and are covered by a layer of ice 3400-3500 m thick. High-frequency radar surveys indicated significant differences in accumulation rates across the lake margins, and revealed areas with almost no accumulation.

Our picture of the Recovery Lakes, and our understanding of how they influence the ice stream, will be refined as data from the expedition are analysed and interpreted by scientists in the US and Norway in the months and years to come. Likewise, analysis of the ice cores and other samples and data collected during the expedition will improve our knowledge of climate variability in East Antarctica during the last 1000 years, and will contribute to a better understanding of the ice mass balance of the region. Automatic weather stations and snow stakes will continue to supply data for some time. There is significant uncertainty about how East Antarctica is changing in terms of temperature and accumulation rates. The Norwegian-American traverse will help rectify this.
Laden with tonnes of ice cores, the expedition rolled into Troll Station on 21 February 2009. The following day, after a climate seminar in Cape Town, environmental ministers and climate advisors from around the world arrived at Troll for a climate study tour. Norwegian Minister of the Environment, Erik Solheim, expressed to the Norwegian press his belief that the meeting will facilitate the formal international climate negotiations in Copenhagen later this year.

During the IPY, 50 or 60 thousand scientists, technicians and crew carried out more than 200 research projects, including 170 that were international collaborative efforts. A wide range of the natural sciences were represented, and many of these projects relied heavily on the technological developments of recent years. For the first time social science was a component of the IPY. There was an emphasis on incorporating indigenous knowledge into the research, as well as involving indigenous peoples as stakeholders with a strong interest in the results. Public outreach and education was another new component, which made good use of the internet and related communication advances. (Along with several other scientific journals, Polar Research has been participating in an IPY outreach project organized by the Arctic Institute of North America: Popularization of Northern Scholarly Articles for Public Interest.) About a third of the IPY projects took place in the Antarctic, which is in many respects poorly understood in relation to its size and its potential role, for example, in global sea-level changes. In the Arctic, some IPY researchers had to contend with unusually mild conditions that compelled them to adjust their plans.

It is precisely this warming, and the resulting retreat of summer sea ice, that may eventually open up greater expanses of the Arctic to hydrocarbon resource exploration, shipping, fishing and tourism. The circumpolar nations are rushing to carve their slices of the Arctic Ocean pie by mapping their continental shelves and other geological features to which they lay claim. (Russia placed its flag on the ocean floor of the North Pole in the summer of 2007, a few months after the start of the IPY.) The better scientific understanding of this region-a goal greatly advanced by the IPY-has never been more urgently needed, but how such knowledge will be put to use in the management of the Arctic is not yet clear. In any event, it is extremely doubtful that anything like the Antarctic Treaty-the unparalleled international agreement that was opened for signature 50 years ago, and dedicated Antarctica to peace and science-will come into force at the opposite end of the world. 
Nonetheless, important steps towards international cooperation over common interests in the Arctic are being made. In April this year, representatives of the eight circumpolar nations convened in Tromsø, Norway, for the Sixth Ministerial Meeting of the Arctic Council, where they signed the Tromsø Declaration. (The NPI hosts the Arctic Council Secretariat at the institute's headquarters in Tromsø.) The agreement states the need for: (i) international cooperation with respect to Arctic search and rescue operations, in the context of increasing maritime activities; (ii) Arctic shipping guidelines, particularly with respect to environmentally sound operations in ice-covered waters; and (iii) developing safety systems for economic activity and infrastructure. The council revised its guidelines for oil and gas exploration, and established a task force on non- $\mathrm{CO}_{2}$ drivers of climate change such as black carbon and methane. Members of the council also agreed on a set of best practices in ecosystem-based ocean management in the Arctic.

Timed to coincide with the assembly of ministers in Tromsø for the Arctic Council meeting, an invitation-only

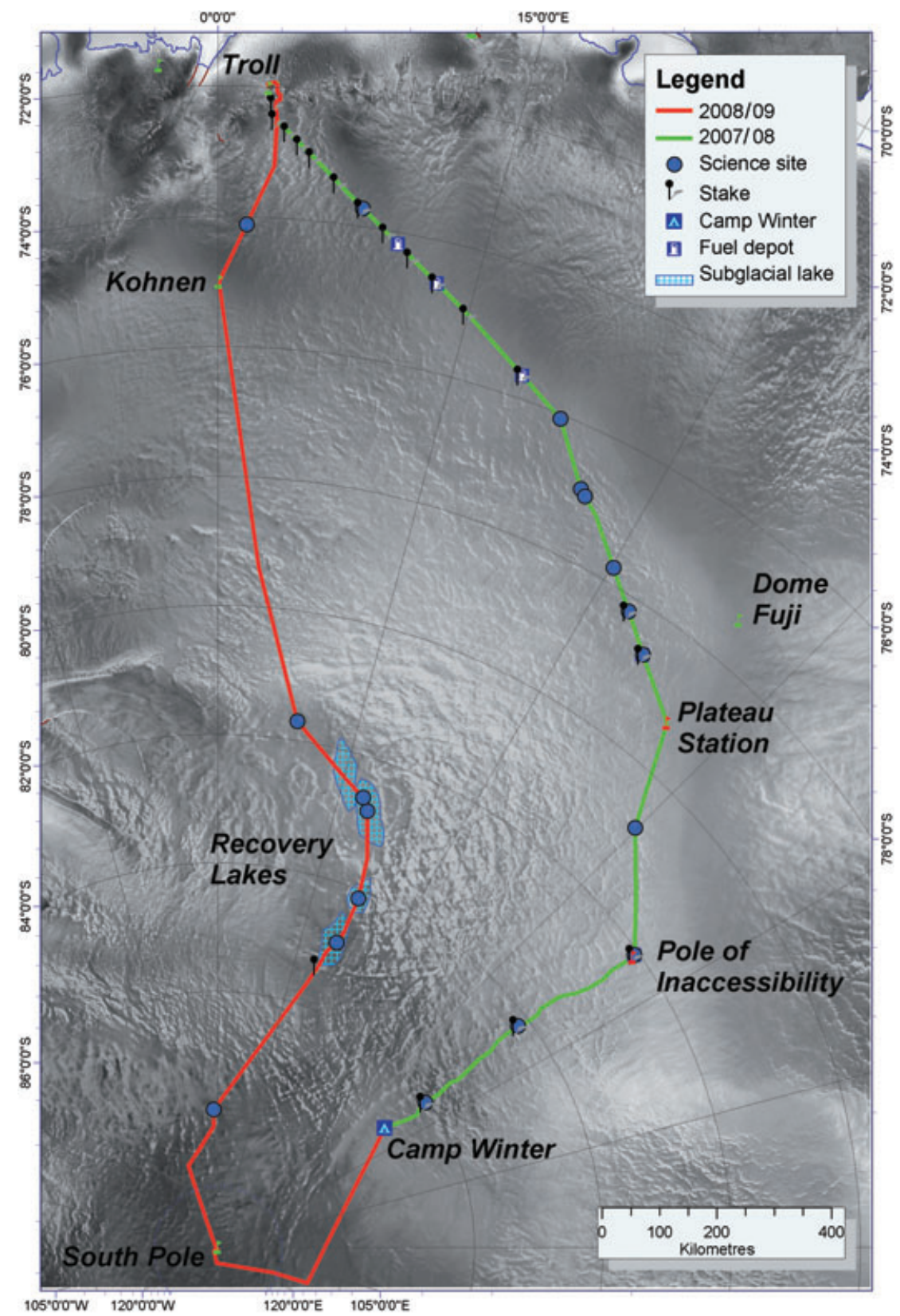

The route taken by the Norwegian-American Scientific Traverse of East Antarctica. In preparation for the second stage of the expedition, vehicles left at Camp Winter at the end of the first stage were driven to the South Pole via a route that skirted the Clean Air and Quiet sectors by the Amundsen-Scott South Pole Station. 


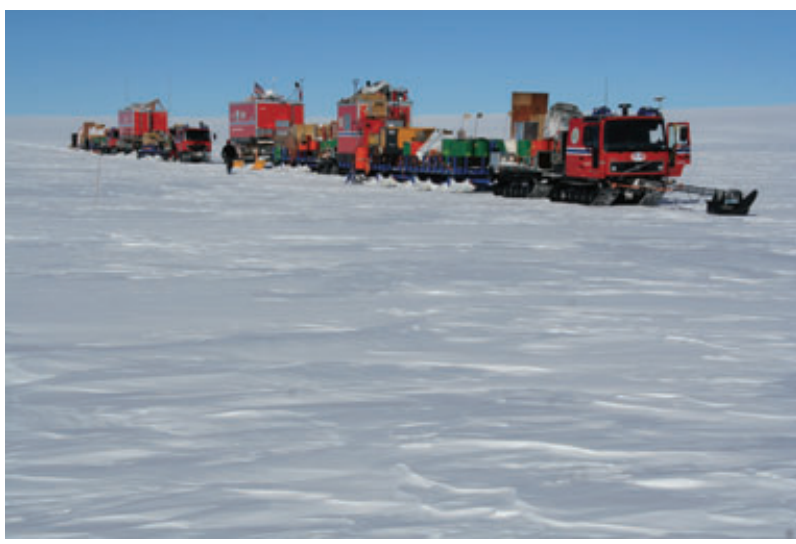

The convoy of tracked vehicles, named after four dogs that made their mark in the history of polar exploration. In the lead, Lasse pulls a sledge loaded with waste, fuel, the main generator and the workshop. Next is Chinook (partially concealed), drawing a sledge with provisions and the residence module. Third, Jack's sledge is loaded with research equipment and the sleeping module. Last, Sembla pulls a sledge bearing more fuel, more scientific equipment and the laboratory. (Photo by Stein Tronstad, courtesy of Norwegian Polar Institute Photo Library.)

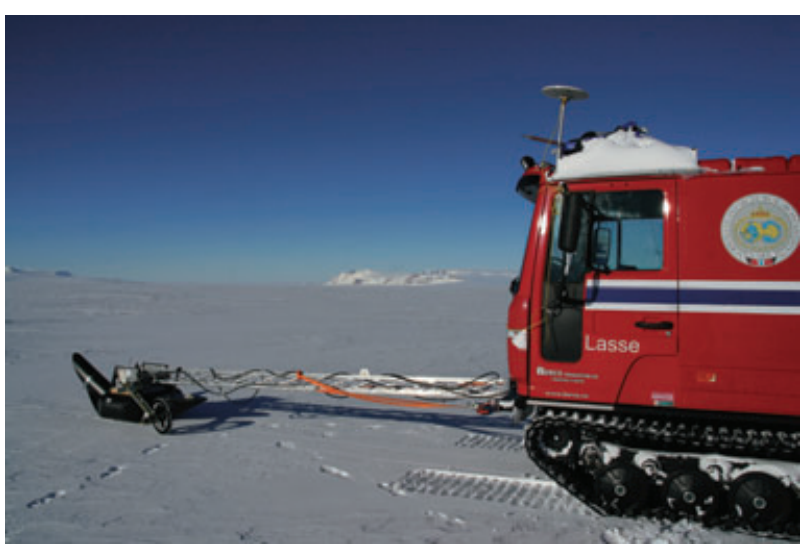

Mounted with radar on a boom, Lasse always led the convoy. The device was developed by the NPI to reduce the chances of vehicles falling into the under-snow crevasses that lie along the expedition's route. (Photo by Stein Tronstad, courtesy of Norwegian Polar Institute Photo Library.)

climate conference of ministers and climate scientists took place on 28 April in Tromsø. The Norwegian Foreign Minister, Jonas Gahr Støre, and former US vice-president, Al Gore, co-hosted the event, entitled Melting Ice: Regional Dramas, Global Wake-up Call. The gathering was seen as an important event in relation to the climate summit in Copenhagen next year.

Norway will host a large international conference in June 2010 to give researchers involved in IPY projects an opportunity to share experiences, ideas and preliminary findings. The IPY Oslo Science Conference will emphasize

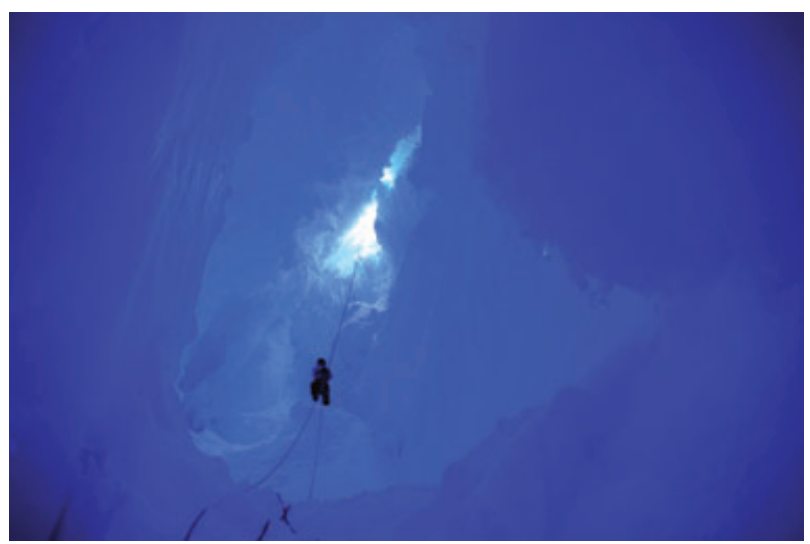

Kirsty Langley lowers herself into one of the biggest crevasses traversed by the expedition. Radar helped the team identify hidden crevasses, but details of the radar pictures needed ground-truthing for interpretation. Exactly how wide was the crevasse? How thick was the snow bridge spanning it? Exploring the caves refined the team's ability to make sense of the radar images, which will benefit future expeditions. (Photo by Stein Tronstad, courtesy of Norwegian Polar Institute Photo Library.)

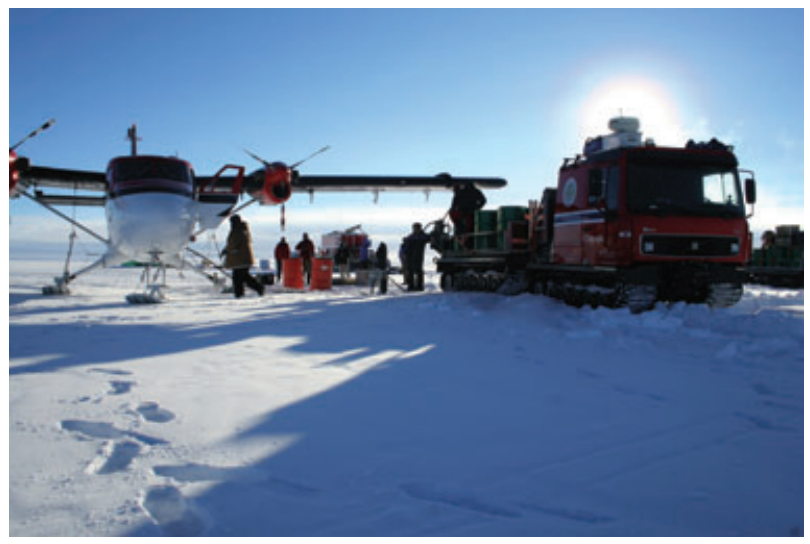

A Twin Otter flew from the South Pole Station to deliver 40 litres of ethanol to the expedition, stopped near Recovery Lake B. A vital (and very expensive) ice drill lay trapped in ice at the bottom of a 92-m-deep borehole. It took four days to retrieve the drill, using the ethanol and a hook improvised on the spot by NPI technician Svein Henriksen. (Photo by Stein Tronstad, courtesy of Norwegian Polar Institute Photo Library.)

the breadth and global impact of polar research during the initiative, and will highlight the multinational and interdisciplinary efforts in research and in the communication of research to the public. Participants will present early scientific results from all the IPY themes, particularly in the areas of: (i) linkages between polar regions and global systems; (ii) past, present and future changes in polar regions; (iii) polar ecosystems and biodiversity; (iv) health and well-being of Northern people; and (v) new frontiers and new directions in polar research. For more information, see http://www.ipy-osc.no/. 


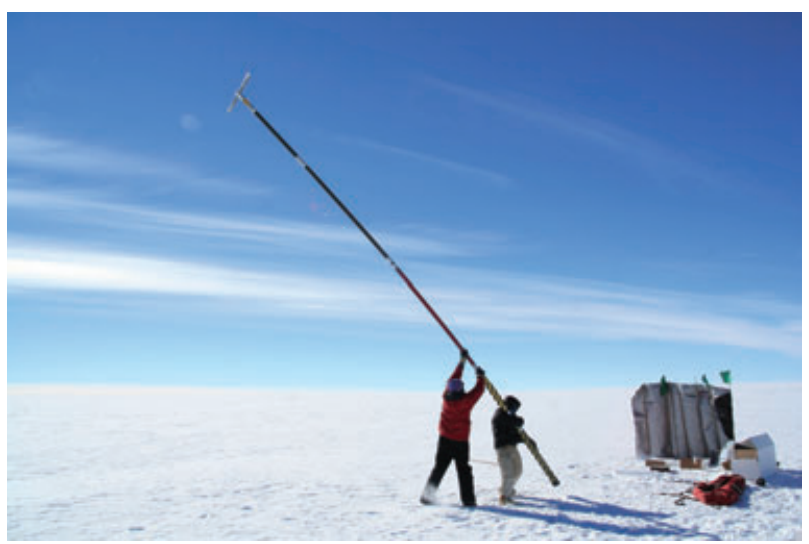

Tom Neumann and Zoe Courville pull up a hand auger with a short ice core. (Photo by Stein Tronstad, courtesy of Norwegian Polar Institute Photo Library.)

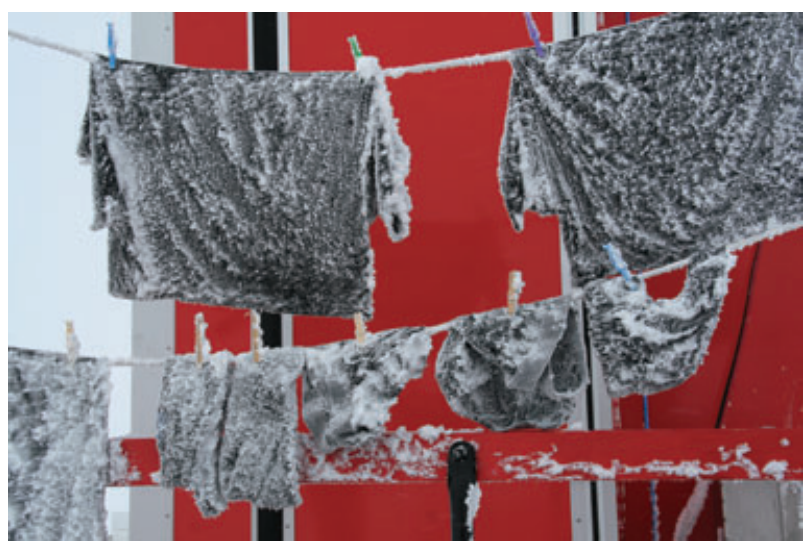

Laundry was washed by hand and hung out to dry. A few hard whacks got off most of the ice. (Photo by Stein Tronstad, courtesy of Norwegian Polar Institute Photo Library.)

Although analysing the results of IPY research will occupy scientists for years, it is already clear that polar research must remain a very high priority, not least on account of the role the polar regions play in the global climate system. In recognition of this, and continuing the momentum of the IPY, the Norwegian Ministry of the Environment has generously funded the establishment of the Centre for Ice, Climate and Ecosystems (ICE) within the NPI. ICE will further strengthen the NPI's climaterelated research. The focus of the centre is threefold: (i) sea ice and snow, especially the way these affect and are affected by climate; (ii) the effect of climate change on ice-associated species and high-latitude ecosystems; and (iii) high-latitude glaciers, and exchanging knowledge about these with scientists investigating high-altitude glaciers. This third topic was the subject of an international conference-High Mountain Glaciers and Challenges Caused by Climate Change-hosted by the NPI in June.

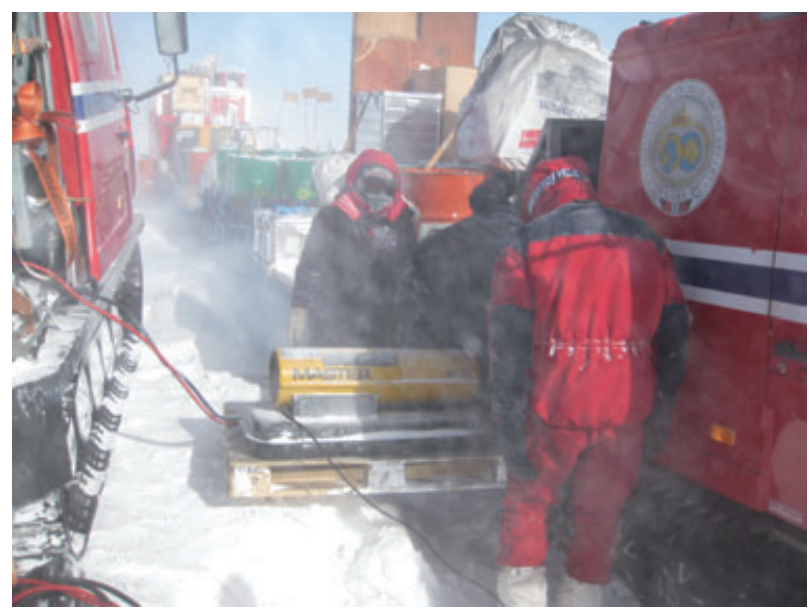

After the last science stop had been made, the temperature dropped to a minimum of $-46^{\circ} \mathrm{C}$ during the night and a storm blew up. It took 8 hours to thaw out the vehicles' motors with heaters and to clear away the snow before the convoy could get going. (Photo by Stein Tronstad, courtesy of Norwegian Polar Institute Photo Library.)

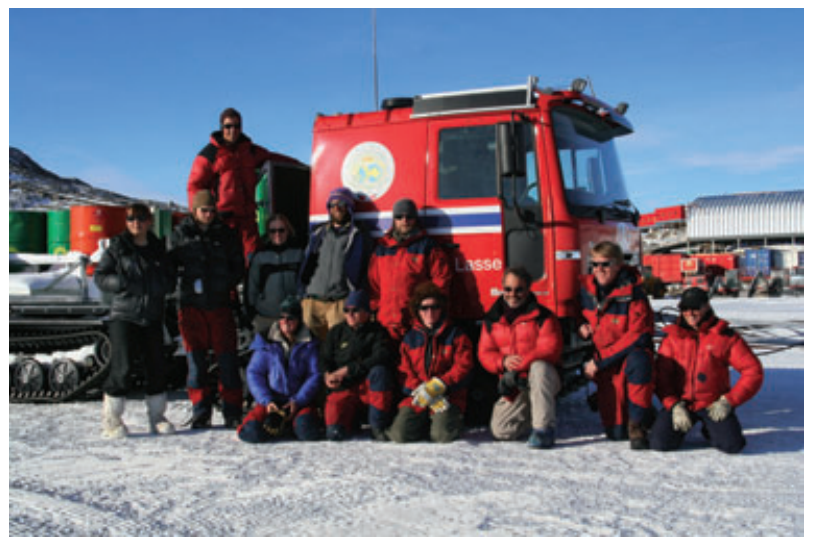

The Norwegian-American team at Troll Station. Kneeling, from left to right: Kirsty Langley (NPI), Svein Henriksen (NPI), Einar Johansen (NPI), Ted Scambos (University of Colorado), Ole Tveiten (NPI) and Lou Albershardt (University of Wisconsin). Standing on the ground, from left to right: Anna Sinisalo (University of Oslo), Andreas Tøllefsen (Norut AS), Zoe Courville (Cold Regions Research and Engineering Laboratory), Tom Neumann (Goddard Space Flight Research Center) and John Guldahl (NPI). Standing on the vehicle: Stein Tronstad (NPI). (Photo courtesy of Norwegian Polar Institute Photo Library.)

Nalan Koç, former head of the NPI's climate research programme, has been appointed leader of the new centre. ICE is advised by an external board comprising representatives of other research institutions in Norway. Rather than constituting a separate institution, ICE is an integral part of the NPI, with many NPI scientists dividing their time between ICE projects and other NPI research activities. A number of new appointments have been made to complement previously existing NPI expertise. 
At the invitation of Norway's Minister of the Environment, Erik Solheim, ministerial delegations from Algeria, Brazil, China, Denmark, Finland, India, Indonesia, Papua New Guinea, South Africa, Sweden, the UK, the US and the EU gathered at Troll Station to learn about climate change. Lord Nicholas Stern, expert on the economics of climate change, was another honoured guest. (Photo by Bertran Kiil, courtesy Norwegian Polar Institute Photo Library.)

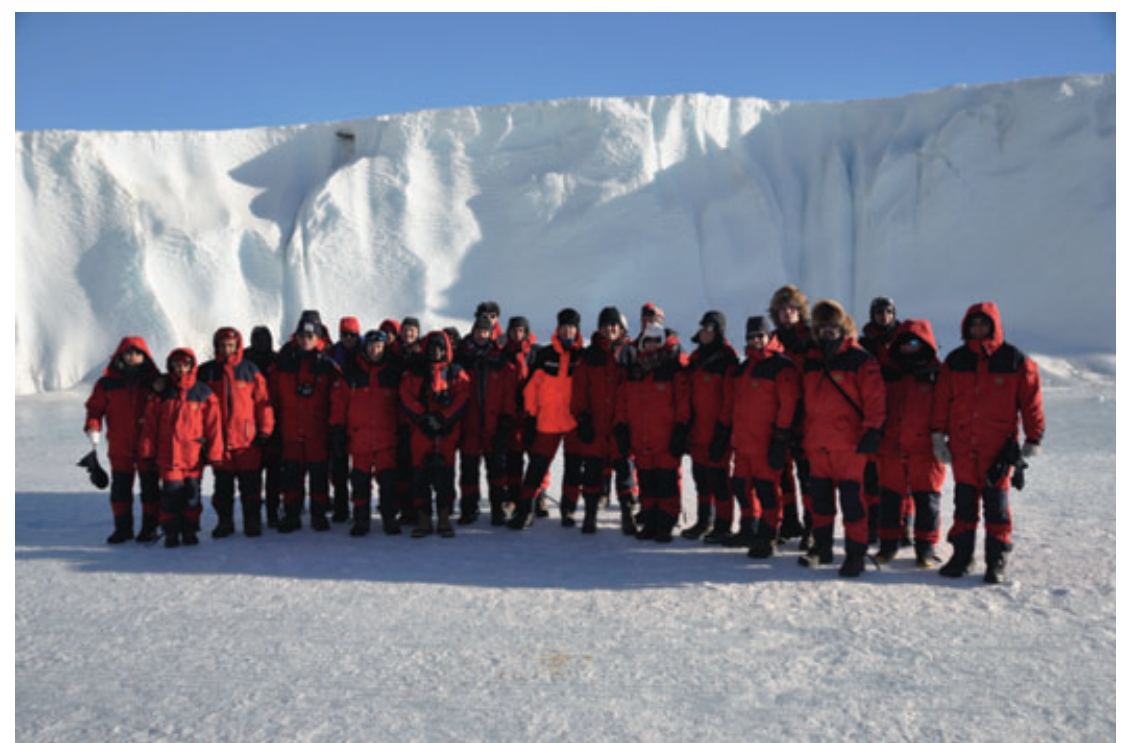

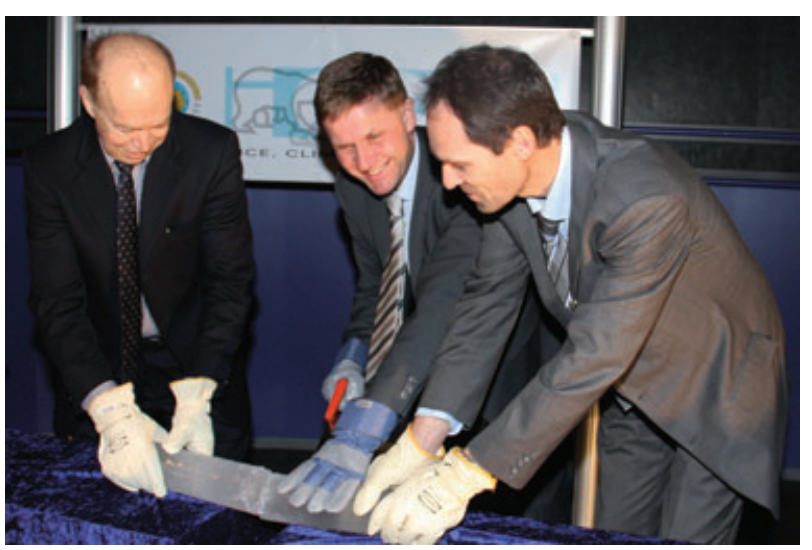

The Norwegian Minister of the Environment, Erik Solheim (middle), opened the new centre for Centre for Ice, Climate and Ecosystems, which was officially established in March 2009-just as the IPY ended. To mark the occasion, Solheim sawed an ice core in two, assisted by James Hansen (left), director of NASA's Goddard Institute for Space Studies, and JanGunnar Winther, director of the NPI. (Photo by Jesper Hansen, courtesy of Norwegian Polar Institute Photo Library.)

One of ICE's flagship research projects is Fimbul Ice Shelf-Top to Bottom. The Fimbul Ice Shelf is 200-400 m thick and hugs Dronning Maud Land, Antarctica. Despite the relatively small size of the shelf, there are indications that Fimbul is one the ice shelves with the greatest meltwater flux in Antarctica. The Fimbul Ice Shelf-Top to Bottom project will combine oceanographic and glaciological approaches to better understand the rate of melting, and the processes determining it. This will improve our understanding of large-scale Weddell Sea ocean processes, and will contribute to better predictions about sea level rise, among other things.

Scientists working on the project will use a variety of means to collect data, including: current meter moorings, installed through boreholes in the ice shelf; conductivitytemperature-depth (CTD) sections, obtained through rifts in the shelf; a weather station placed near the ice front; radar and ground surveys; measurements of snow accumulation and remote sensing. Unique data obtained during the IPY project Marine Mammal Exploration of the Oceans Pole to Pole, in which CTD tags were deployed on deep-diving marine mammals in the Arctic and Antarctic, have helped lay the groundwork for the project.

It's been a busy year for the NPI and the pace shows no signs of slackening. In Norway and in other countries, huge stores of IPY data have now to be worked up, new research programmes are being conceived to address questions raised by the old ones and plans are being made to sustain polar monitoring systems, such as the Sustaining Arctic Observing Networks and the Southern Ocean Observing System. In the meantime, the IPY Data and Information Service is working to build a comprehensive IPY data system through a network of data centres, repositories and distribution systems. Leaders of IPY projects agreed to adhere to the IPY Data Policy, the requirements of which include the full, free and timely release of IPY data, with limited exceptions. It will be interesting to see the level of compliance with this, and, eventually, how the data are shared, recombined and used. This will be an important legacy of the IPY.

Helle V. Goldman Chief Editor 